\section{Point: high-sensitive troponin assays - a valuable tool for astute physicians}

\author{
Mario Plebani, Martina Zaninotto \\ Department of Laboratory Medicine, \\ University of Padua, Italy
}

\section{Dear Editor,}

A large body of evidence has been collected in the last decade to demonstrate the clinical value of cardiac troponins, both cardiac troponin I (cTnI) and T (cTnI), as reference biochemical markers of myocardial injury. ${ }^{1,2}$ In addition, cardiac troponins assays have been continuously improved over time regarding their specificity and sensitivity. It is widely demonstrated that analytical performances strongly affect the clinical value of any laboratory test, and this is particularly true for cardiac troponins, as these biomarkers play a pivotal role in clinical decision-making and in management of patient with chest pain and coronary diseases. ${ }^{3,4}$ Therefore, the increasing debate about the pros and cons of the new generation assays, the so-called high-sensitivity troponins, may create concern and confusion. Aim of this paper is to briefly summarize the advantages of the new generation assays for cardiac troponins measurement and to highlight the need to avoid any confusion in the clinical reasoning.

The starting point is the evidence that the search for more sensitive methods is not a laboratory lie nor a manufacturer enforcement to introduce new and more costly diagnostic systems, but an effective clinical goal. ${ }^{5}$

In all documents published in the last several years concerning the universal definition of myocardial infarction, ${ }^{6,7}$ the criteria for the diagnosis of acute myocardial infarction (AMI) include a rising and/or falling patterns of troponins values with at least one $>99^{\text {th }}$ percentile value measured in a reference population consisting of apparently healthy individuals free from heart disease. The same guidelines recommend that such a decision level must be measured with an imprecision [coefficient of variation (CV)] less than or equal to $10 \%$.

At the time of those publications, in particular the first consensus document, ${ }^{1}$ the recommended quality specifications were not satisfied by commercially available methods for cTnI and cTnT assays. ${ }^{8}$ Available methods, therefore, have been classified on the basis of the gap between the desirable (10\%) and effective analytical $\mathrm{CV}$ at the $99^{\text {th }}$ percentile. ${ }^{9}$ This, in turn, forced manufacturers to develop assays with an improved precision at the cutoff level and laboratory professionals to adopt more sensitive assays to comply with the clinical goal.

As a result of the efforts to develop improved methods, new generations assays for troponins have been developed. These have unfortunately been identified by different names (e.g. ultra-sensitive, highly sensitive, high performance, etc.), thus making the comprehension of their effective characteristics cumbersome. ${ }^{10}$ In order to overcome the barrier for an accurate interpretation of troponin values in clinical practice, and to designate the sensitive assays, a two tiers system has been proposed and widely accepted. ${ }^{11}$ This system is based on two criteria: i) the total imprecision at the $99^{\text {th }}$ percentile, and ii) the ability to measure normal values below the $99^{\text {th }}$ percentile. Both criteria are supported by a clinical rationale, as the low $\mathrm{CV}$ at the cut-off level reduces the analytical uncertainty around the decision level. This, in turn, appears to be an essential issue as any increase of troponin levels is an index of myocardial damage. In addition, a growing body of evidence demonstrates that detectable levels of troponins under the cut-off are associated with chronic myocardial diseases and poor clinical outcomes. ${ }^{12}$ The proposed score, however, is not a dogma and new insights from recently published papers have stressed the need to add a further criterion, i.e. the effects on clinical outcomes. ${ }^{13}$ Indeed, that the effects on clinical outcomes represent the top of the hierarchy for setting analytical quality specifications for all tests, including cardiac troponins, should be not overlooked. Therefore, this point should reserve major concern in the near future.

On the basis of the collected evidence, major advantages of high-sensitive assays for cardiac troponins should be summarized as in the following paragraphs.

First, high-sensitive assays comply with clinical recommendations, as previously described.

Second, high-sensitive assays assure an earlier detection of myocardial damage, thus allowing an early diagnosis in patients with acute chest pain as well as a rapid and reliable rule-out in emergency. A body of evidence is available to document that the diagnostic accuracy of high-sensitivity assays is higher than conventional methods and, in particular, is significantly higher in the first hours after chest pain and/or patient admission.,10 This, in turn, makes the concurrent request of additional biochemical markers of myocardial ischemia or injury inappropriate and useless.

Third, high-sensitive assays allow to rapidly verify the kinetics patterns of troponin release in order to identify those complying with the universal definition of myocardial infarction. In fact, using sensitive assays, troponin concentrations change very rapidly within shorter time intervals, thus allowing a more reliable
Correspondence: Mario Plebani, Department of Laboratory Medicine, University of Padua, via Giustiniani 2, 35128 Padua, Italy.

Tel. +39.049.8212792 - Fax: +39.049.663240.

E-mail: mario.plebani@unipd.it

Key words: high-sensitivity, troponin, assays.

Contributions: the authors contributed equally.

Conflict of interests: the authors declare no potential conflict of interests.

Note: this Letter to the Editor relates to Casagranda I, Cavazza M, Clerico A, et al. Proposal for the use in emergency departments of cardiac troponins measured with the latest generation methods in patients with suspected acute coronary syndrome without persistent ST-segment elevation. Emerg Care J 2013;9:e14.

Received for publication: 30 April 2013. Accepted for publication: 27 May 2013.

This work is licensed under a Creative Commons Attribution 3.0 License (by-nc 3.0).

CCCopyright M. Plebani and M. Zaninotto, 2013

Licensee PAGEPress, Italy

Emergency Care Journal 2013; 9:e15

doi:10.4081/ecj.2013.e15

rule-in process, and a reliable and more efficient rule-out strategy, which is even more important in emergency settings. ${ }^{14}$

Fourth, in real life high-sensitive troponins improve the diagnostic accuracy without significantly increasing the admission rates, as recently documented by Mion et al..$^{15}$

Fifth, high-sensitive assays improve the risk stratification even in patients with normal concentrations of cardiac troponins measured with conventional assays. ${ }^{16}$

Sixth, high-sensitive assays improve the detection of minor myocardial damage in several clinical conditions, particularly in chemotherapy monitoring as well as in the administration of other drugs with side effects, thus allowing an early identification of myocardial damage. ${ }^{17}$ It has been demonstrated that the early identification of myocardial damage using cardiac troponin assays may result in improved outcomes and reduction of the incidence of heart failure. ${ }^{18,19}$

In summary, a robust evidence has been collected to demonstrate the clinical effectiveness of high-sensitive assays for cardiac troponin. However, it should be highlighted that cardiac troponin, particularly when assayed with highsensitive methods, should be viewed as a marker of myocardial damage, not as marker of ischemic diseases, nor as a marker of irreversible myocardial damage. Although increased cTn in settings other than acute coronary syndrome (ACS) or heart failure is 
frequently considered as a clinical confounder, the astute physician must be able to interpret cTn as a dynamic marker of myocardial damage, using clinical acumen to determine the source and significance of any reported cTn increase..$^{20}$ Just as a tool is only as good as its operator, a diagnostic test can be as good as its interpretation and, therefore, the more sophisticated is, the more sophisticated should be its interpretation. ${ }^{21}$ In particular, the more appropriate is the test request, the more appropriate is its right interpretation in the proper clinical context. Viceversa, the more inappropriate is the request, the more inappropriate will be its interpretation and utilization. In the case of cTn high-sensitive assays, the supposed decreased specificity of the test is related to myocardial injuries, which in turn is unrelated to ischemic events. If appropriately interpreted and followed, these increases may result in improved diagnoses and patient management. High-sensitivity troponin assays offer potential advantages over the conventional assays, the major problem with them being often an inappropriate request and interpretation of the results, not the marker itself.

\section{References}

1. Alpert JS, Thygesen K, Antman E, Bassand JP. Myocardial infarction redefined: a consensus document of the Joint European Society of Cardiology/American College of Cardiology Committee for the redefinition of myocardial infarction. J Am Coll Cardiol 2000;36:959-69.

2. Thygesen K, Alpert JSA, Jaffe AS, et al. The writing group on behalf of the joint ESC/ACCF/AHA/WHF task force for the universal definition of myocardial infarction. Circulation 2012;126:2020-35.

3. Keller T, Zeller T, Peetz D, et al. Sensitive troponin I assay in early diagnosis of acute myocardial infarction. New Engl $\mathrm{J}$ Med 2009;361:868-77.

4. Mills NL, Churchhouse AM, Lee KK, et al. Implementation of a sensitive troponin I assay and risk of recurrent myocardial infarction and death in patients with suspected acute coronary syndrome. JAMA-J Am Med Assoc 2011;305:1210-6.

5. Haaf P, Drexler B, Reichlin T, et al. Highsensitivity cardiac troponin in the distinction of acute myocardial infarction from acute cardiac noncoronary artery disease. Circulation 2012;126:31-40.

6. Thygesen K, Alpert JS, White HD. The writing group on behalf of the joint ESC/ACCF/AHA/WHF task force for the redefinition of myocardial infarction. J Am Coll Cardiol 2007;50:2173-95.

7. Thygesen K, Alpert JS, Jaffe AS, et al. Third universal definition of myocardial infarction. Eur Heart J 2012;33:2551-67.

8. Apple FS, Jesse RL, Newby LK, et al. National academy of clinical biochemistry and IFCC committee for standardization of markers of cardiac damage laboratory medicine practice guidelines: analytical issues for biochemical markers of acute coronary syndromes. Clin Chem 2007;53:547-51.

9. Panteghini M, Pagani F, Yeo KT, et al. Committee on standardization of markers of cardiac damage of the IFCC. Evaluation of imprecision for cardiac troponin assays at low-range concentrations. Clin Chem 2004;50:327-32.

10. Thygesen $\mathrm{K}$, Mair J, Katus $\mathrm{H}$, et al. Recommendations for the use of cardiac troponin measurement in acute cardiac care. Eur Heart J 2010;31:2197-206.

11. Apple FS. A new season for cardiac troponin assays: it's time to keep a scorecard. Clin Chem 2009;55:1303-6.

12. Meune C, Reichlin T, Irfan A, et al. How safe is the outpatient management of patients with acute chest pain and mildly increased cardiac troponin concentrations? Clin Chem 2012;58:916-24.

13. Venge P, Lindahl B. Cardiac troponin assay classification by both clinical and analytical performance characteristics: a study on outcome prediction. Clin Chem 2013;59: 976-81.

14. Body R, Carley S, McDowell G, et al. Rapid exclusion of acute myocardial infarction in patients with undetectable troponin using a high-sensitivity assay. J Am Coll Cardiol 2011;58:1332-9.

15. Mion MM, Bragato G, Zaninotto M, et al. Effect of last generation cardiac troponin assay on patients' management: a real world emergency department experience. Clin Chim Acta 2013;418:77-8

16. Latini R, Masson S, Anand IS, et al. Prognostic value of very low plasma concentrations of troponin $\mathrm{T}$ in patients with stable chronic heart failure. Circulation 2007;116:1242-9.

17. Regan WJ, York M, Berridge B, et al. Comparison of cardiac troponin I and T, including the evaluation of an ultrasensitive assay, as indicators of doxorubicininduced cardiotoxicity. Toxicol Pathol (2013) (in press).

18. Tsutamoto T, Kawahara C, Nishiyama K, et al. Prognostic role of highly sensitive cardiac troponin I in patients with systolic heart failure. Am Heart J 2010;159:63-7.

19. Xue Y, Clopton P, Peacock WF, Maisel AS Serial changes in high-sensitive troponin I predict outcome in patients with decompensated heart failure. Eur J Heart Fail 2011;13:37-42.

20. Kelley WE, Januzzi JL, Christenson RH. Increases of cardiac troponin in conditions other than acute coronary syndrome and heart failure. Clin Chem 2009;55:2098112.

21. Diamond GA, Kaul S. How would the reverend Bayes interpret high sensitivity troponin? Circulation 2010;121:1172-5. 